\title{
Drug Predictive Cues Activate Aversion-Sensitive Striatal Neurons That Encode Drug Seeking
}

\author{
Daniel S. Wheeler, ${ }^{\star}$ Mykel A. Robble, ${ }^{\star}$ Emily M. Hebron, Matthew J. Dupont, Amanda L. Ebben, and Robert A. Wheeler \\ Department of Biomedical Sciences, Marquette University, Milwaukee, Wisconsin 53233
}

\begin{abstract}
Drug-associated cues have profound effects on an addict's emotional state and drug-seeking behavior. Although this influence must involve the motivational neural system that initiates and encodes the drug-seeking act, surprisingly little is known about the nature of such physiological events and their motivational consequences. Three experiments investigated the effect of a cocaine-predictive stimulus on dopamine signaling, neuronal activity, and reinstatement of cocaine seeking. In all experiments, rats were divided into two groups (paired and unpaired), and trained to self-administer cocaine in the presence of a tone that signaled the immediate availability of the drug. For rats in the paired group, self-administration sessions were preceded by a taste cue that signaled delayed drug availability. Assessments of hedonic responses indicated that this delay cue became aversive during training. Both the self-administration behavior and the immediate cue were subsequently extinguished in the absence of cocaine. After extinction of self-administration behavior, the presentation of the aversive delay cue reinstated drug seeking. In vivo electrophysiology and voltammetry recordings in the nucleus accumbens measured the neural responses to both the delay and immediate drug cues after extinction. Interestingly, the presentation of the delay cue simultaneously decreased dopamine signaling and increased excitatory encoding of the immediate cue. Most importantly, the delay cue selectively enhanced the baseline activity of neurons that would later encode drug seeking. Together these observations reveal how cocaine cues can modulate not only affective state, but also the neurochemical and downstream neurophysiological environment of striatal circuits in a manner that promotes drug seeking.
\end{abstract}

Key words: addiction; cocaine; dopamine; electrophysiology; relapse; voltammetry

\section{Introduction}

Informed by drug addicts' emotional and physiological reactions to drug-associated cues (Childress et al., 1999; Garavan et al., 2000), theories of drug addiction and relapse often posit an influence of cues on drug-seeking behavior (Di Chiara, 1999; Robinson and Berridge, 2003; Everitt et al., 2008). These theories often note the desirability of these incentivized cues, which have a well known neural representation in both mesolimbic dopamine (DA) signaling and cell firing in the nucleus accumbens (NAc). Such signals of immediate drug reward reliably increase striatal DA (Phillips et al., 2003), activate NAc neurons (Hollander and Carelli, 2007), and promote drug seeking (Shaham et al., 2003).

However, human addicts report that drug-associated cues induce negative feelings related to drug craving and anxiety that predict relapse (Sinha et al., 2000, 2003). The ability of drug cues

Received Nov. 23, 2014; revised April 2, 2015; accepted April 4, 2015.

Author contributions: D.S.W., M.A.R., and R.A.W. designed research; D.S.W., M.A.R., E.M.H., M.J.D., and A.L.E. performed research; D.S.W., M.A.R., E.M.H., M.J.D., and A.L.E. analyzed data; D.S.W., M.A.R., and R.A.W. wrote the paper.

This work was supported by NIDA Grant DA-025679. We thank Dr Robert Twining for technical advice, Austin Bohn and Adam Kirry for technical support, and Dr Mitchell Roitman and Chung-Lung Chan for comments on the paper.

The authors declare no competing financial interests.

${ }^{*}$ D.S.W. and M.A.R. contributed equally to this work.

Correspondence should be addressed to Dr Robert A. Wheeler, Department of Biomedical Sciences, Marquette University, 561 North $15^{\text {th }}$ Street, SC 446, Milwaukee, WI 53233. E-mail: robert.wheeler@mu.edu.

DOI:10.1523/JNEUROSCI.4823-14.2015

Copyright $\odot 2015$ the authors $\quad 0270-6474 / 15 / 357215-11 \$ 15.00 / 0$ to cause negative affect can be studied in animal models, and such studies have demonstrated that predictors of delayed drug access can cause avoidance (Tzschentke, 1998; Grigson and Twining, 2002), negative affect (Wheeler et al., 2008), a reduction of DA (Wheeler et al., 2011), and enhanced excitatory activity in reward circuitry (Wheeler et al., 2008). Additionally, the degree of aversion correlates with enhanced drug-seeking motivation (Wheeler et al., 2011; Nyland and Grigson, 2013; Colechio et al., 2014). The fact that appetitive and aversive stimuli can differentially affect striatal circuitry has led us to hypothesize that aversive stimuli disinhibit a distinct aversion-sensitive striatal circuit that also drives drug seeking (Twining et al., 2014), possibly as an avoidance behavior (Baker et al., 2004; Koob and Le Moal, 2008). Although recent studies have shown that correcting a reduction in DA signaling can attenuate drug taking and seeking (Twining et al., 2014; Willuhn et al., 2014), it is not clear how an aversive stimulus that decreases DA signaling simultaneously impacts striatal cell firing to promote drug seeking.

Here we directly tested whether an aversive cue can cause drug seeking, if it does so in a state of low DA tone, and if it activates neurons that encode the drug-seeking act. Additionally, we investigated the impact of the aversive drug cue on the processing of another drug-associated stimulus and drug-seeking behavior. The potential change in the physiological response to a proximate cocaine cue (i.e., a cue that signals immediate drug infusion) was of particular interest because aversive stimuli can interact synergistically with proximate drug cues to drive drug seeking (Liu and 
a

Taste-drug Training, Extinction, and Reinstatement Testing

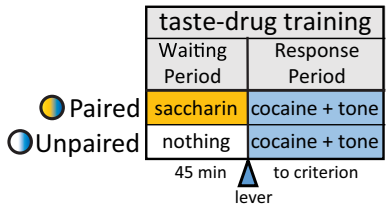

b

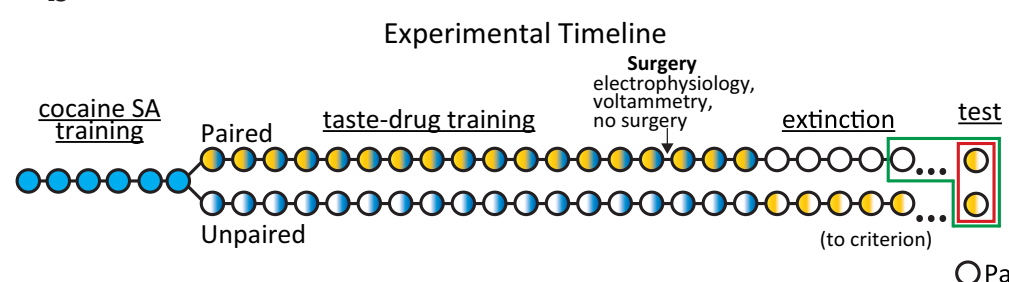

nothing saline + tone

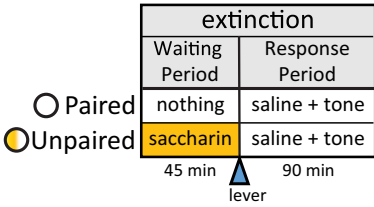

\begin{tabular}{|c|c|}
\hline \multicolumn{2}{|c|}{ extinction } \\
\hline Waiting & Response \\
\hline
\end{tabular}

$45 \mathrm{~min} \triangle_{\text {lever }} 90 \mathrm{~min}$

C \begin{tabular}{lll} 
Saccharin & saline + tone \\
\cline { 2 - 2 } & saccharin & saline + tone \\
\hline
\end{tabular}

\begin{tabular}{c} 
OUnpaired \\
\cline { 2 - 3 } $45 \mathrm{~min} \quad \Delta \quad 90 \mathrm{~min}$
\end{tabular}

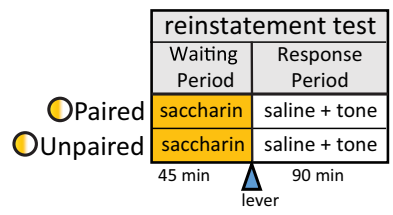



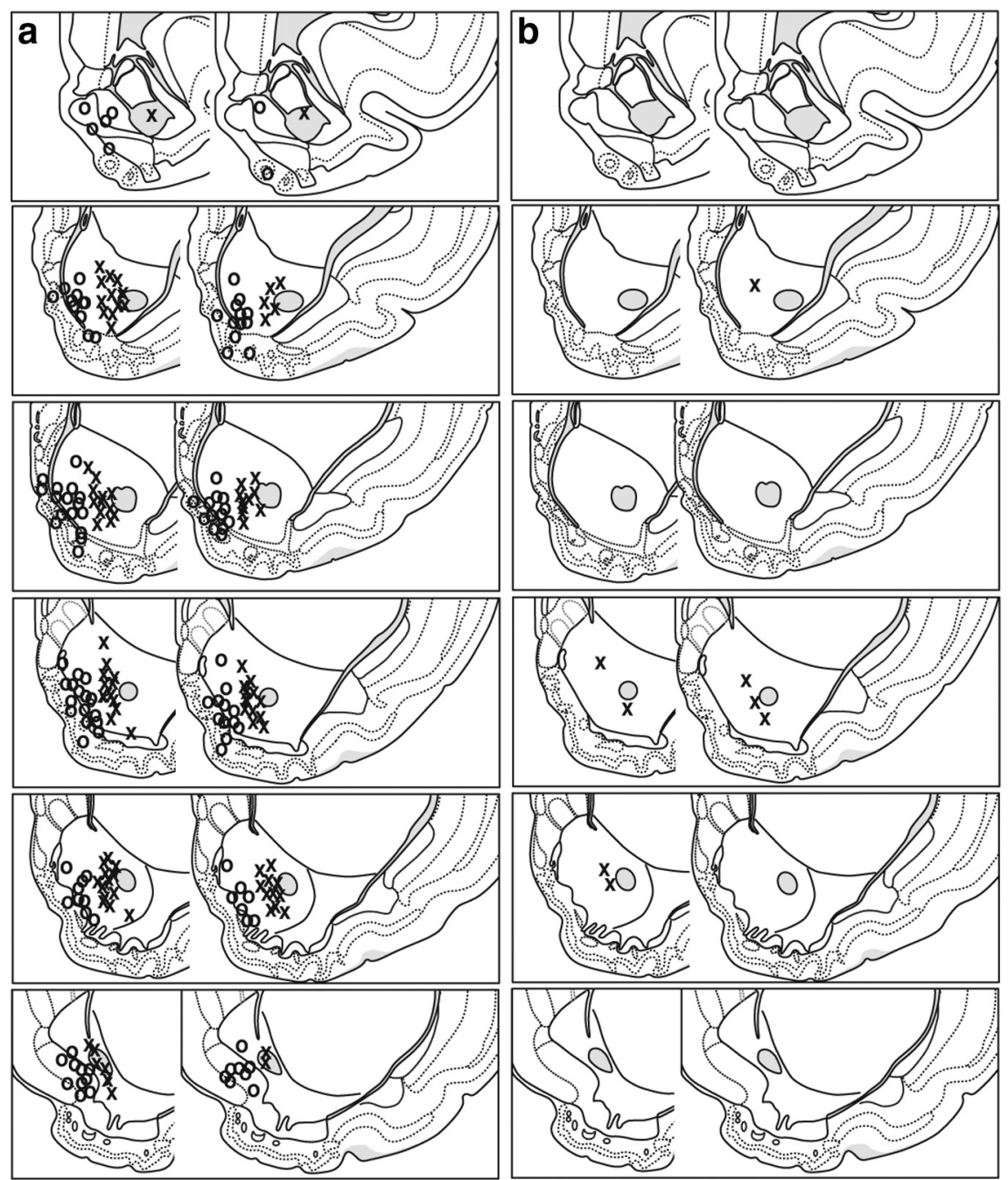

Figure 2. Electrode placements. $\boldsymbol{a}$, Electrophysiology electrode placements in the NAcC (Xs) and NAcS (Os) in paired (left; $n=$ 16) and unpaired (right; $n=9$ ) rats. $\boldsymbol{b}$, Voltammatry electrode placements in paired (left; $n=4$ ) and unpaired (right; $n=4)$ rats.

speaker capable of producing a $65 \mathrm{~dB} 1 \mathrm{kHz}$ tone was located on the left sidewall. Under each chamber, a camera was positioned to allow for recording behavioral responses (taste reactivity). The chamber floor was clear acrylic glass and a house light was positioned on the door of the sound attenuating chamber, outside of the operant chamber, to ensure recording quality.

Self-administration training. Following catheter implantation, subjects were allowed to recover until they reached presurgery bodyweight. Subjects were then food restricted to $90 \%$ bodyweight, and trained to press one of the two levers for food pellets. Upon acquisition of lever-press behavior, subjects were trained to self-administer cocaine on a fixedratio one schedule of reinforcement. The beginning of each cocaine selfadministration session was signaled by the entry of both levers into the box and the illumination of two cue lights. Responses on the active lever resulted in a $3 \mathrm{~s}$ cocaine infusion $(0.25 \mathrm{mg} / 0.1 \mathrm{ml})$ accompanied by cue-light offset, onset of a $5 \mathrm{~s}$ tone, and a $20 \mathrm{~s}$ timeout period. Responses on the active lever during the timeout resulted in no programmed consequences and are not included in the data analyses. The conclusion of the time out period was signaled by cue light onset. Each session was completed only when each subject reached a maximum infusion cap (detailed below).

Self-administration sessions occurred in a series of six experimentercontrolled $6 \mathrm{~d}$ cycles consisting of $3 \mathrm{~d}$ of cocaine self-administration and $3 \mathrm{~d}$ without cocaine access in the home cage. The maximum number of infusions taken per session increased each cycle from a 20 infusion cap in the first cycle, to a 50 infusion cap in the final cycle. Upon completion of cycles 1 and 2, subjects were separated into groups, counterbalanced for weight and average latency to reach to the infusion cap in the second cycle. Rats were initially trained for six sessions without a waiting period to balance the groups and to ensure the acquisition of a tone-cocaine association independent from saccharin exposure. For paired rats, all subsequent cocaine self-administration sessions were preceded by a $45 \mathrm{~min}$ waiting period during which each subject received 45 intraoral saccharin infusions $(0.15 \% ; 0.2 \mathrm{ml} / 6 \mathrm{~s} ; 1 \mathrm{inf} /$ min). Unpaired subjects received an equivalent waiting period with no taste before cocaine access.

Extinction and reinstatement. Upon completion of six cycles of cocaine self-administration all subjects were transitioned into the extinction phase. Before every extinction session, unpaired rats received 45 intraoral infusions of saccharin, whereas paired rats experienced a waiting period. Following the saccharin period, a 90 min extinction session began in which presses on the formerly active lever resulted in cue light offset, tone onset, and an infusion of saline. After a minimum of five extinction sessions, subjects were tested for reinstatement when they registered an average of 10 presses or less on the formerly active lever (excluding presses made during the $20 \mathrm{~s}$ time out period) over two consecutive sessions. Extinction responding was analyzed with a mixed ANOVA comparing the paired and unpaired groups across matched extinction sessions.

Once each subject reached extinction criteria they were tested for saccharin-induced reinstatement of cocaine seeking. This session was procedurally identical to an extinction session with the exception that all subjects received saccharin infusions. Reinstatement was assessed by comparing responding in the paired group at test with the final extinction session in both the paired and unpaired groups using $t$ tests. To assess the relationship between reinstatement behavior and aversion, a regression analysis was performed (Pearson's $R$ ). Because of variability in baseline rates of lever pressing at the end of extinction, a reinstatement ratio was computed for the regression analysis by dividing the total number of lever presses during test by the sum of number of lever presses during test and extinction.

Taste reactivity scoring/analysis. Taste reactivity was analyzed in a frame-by-frame analysis using digital video recorded on the test session in paired and unpaired rats. Appetitive and aversive responses were counted in the saccharin period using the technique of Grill and Norgren (1978). Bouts of "wet dog shaking," paw flailing, and mouth movements that matched the "triangle" shape for a duration exceeding $90 \mathrm{~ms}$ were counted as aversive. Instances in which the tongue protruded and crossed the midline were counted as appetitive. The rates of aversive and appetitive events (per trial) were computed for each animal. Taste reactivity data were analyzed with a mixed ANOVA and subsequent planned comparisons of appetitive and aversive taste reactivity (events/trial) in the paired and unpaired groups.

Voltammetry testing and data collection. Subjects underwent fast-scan cyclic voltammetry surgery after their 15 th session of cocaine selfadministration training. Following recovery, subjects received their final $3 \mathrm{~d}$ of self-administration and extinction as previously described. To familiarize the rats with the recording situation, the VTA stimulating electrode was harnessed to a rotating commutator (Crist Instruments) during at least one of the final extinction sessions. Once subjects reached extinction criteria DA responses to saccharin and tone were measured. A 
carbon fiber electrode was lowered into the NAcC. The fiber was held at $-0.4 \mathrm{~V}$ against $\mathrm{Ag} / \mathrm{AgCl}$ between scans and then driven to $+1.3 \mathrm{~V}$ and back in a triangular fashion at 400 $\mathrm{V} / \mathrm{s}$ for each voltammetric measurement. The application of this triangle waveform causes oxidation and reduction of chemical species that are electroactive within this potential range, producing a change in current at the carbon fiber. Specific analytes (including dopamine and $\mathrm{pH}$ ) are identified by plotting these changes in current against the applied potential to produce a cyclic voltammogram (Heien et al., 2004, 2005). The current arising from electrode processes was removed by using background subtraction. For data collected during testing, the background period was taken as the minima during the $10 \mathrm{~s}$ before saccharin or cue presentation. This practice does not subtract the presence of phasic dopamine release events because the background was explicitly selected for the absence of dopamine signals. Measurements were made every $100 \mathrm{~ms}$ and, after driving the electrode into the NAc core, the electrode equilibrated for $40 \mathrm{~min}$ before any data were collected. The position of the microelectrode was then optimized by monitoring the presence of spontaneously occurring dopamine release events (Roitman et al., 2008; Wheeler et al., 2011). Once this was observed, the electrode was locked in place and data collection proceeded. The experiment consisted of a 20 min baseline dopamine monitoring period, then a 45 min saccharin delivery period, followed by a 45 min tone test period during which the proximate cocaine cues (tone onset and cue light offset) were presented every $90 \mathrm{~s}$. Orofacial expressions during saccharin admin-

istration were recorded and scored. Following the conclusion of testing, several electrical stimulation trains that varied in number of pulses $(1,2$, 5,10 , and 20) were administered for the generation of a training set for principal component analysis for the detection of dopamine and $\mathrm{pH}$ changes during the behavioral session. Due to technical limitations of our voltammetry testing apparatus, DA was not measured during lever-press behavior.

Analyte identification and quantification were achieved using principal component regression analysis described previously in detail (Heien et al., 2004). All data presented here fit the resulting model at the $95 \%$ confidence level. Briefly, training sets were generated from backgroundsubtracted cyclic voltammograms collected during and after electrical stimulations. At least 10 voltammograms were obtained for DA and $\mathrm{pH}$. The resulting current amplitude was converted to DA concentration based on calibration of the electrode in a flow injection analysis system after the in vivo experiment. To convert current due to oxidation of DA, $500 \mathrm{~nm}$ and $1 \mu \mathrm{M}$ dopamine in a buffer, $\mathrm{pH} 7.4$, were used in the flowinjection analysis system. Data from each saccharin or cue probe presentation were background subtracted using a $1 \mathrm{~s}$ block at the local minima in the $10 \mathrm{~s}$ before presentation. The resultant current changes over time were converted into DA concentrations over time using a principle component regression.

Voltammetry data analysis. For each rat, trials were aligned to saccharin or tone presentation and averaged together. To analyze the acute effects of saccharin on DA, average concentration during a baseline epoch (10 s before infusion onset) was compared with average concentration during an effect epoch (10 s after infusion onset). Additionally, the diffuse effect of saccharin on non-time-locked DA was examined by blocking baseline epoch measurements into thirds (early, middle, and late). Unlike the acute dopaminergic response to saccharin, which last several seconds, the observed effect of the tone was rapid $(\sim 1 \mathrm{~s})$. Thus, to analyze the effect of the tone on DA concentration, the peak DA concen- b

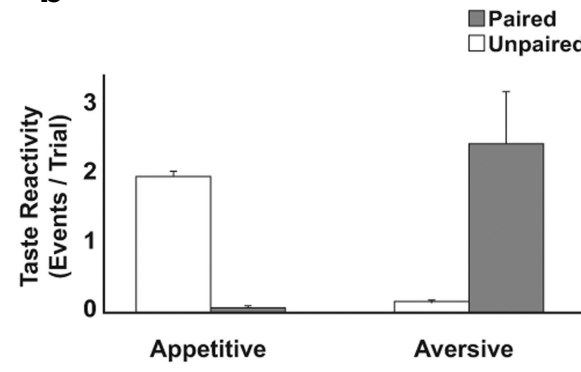

d

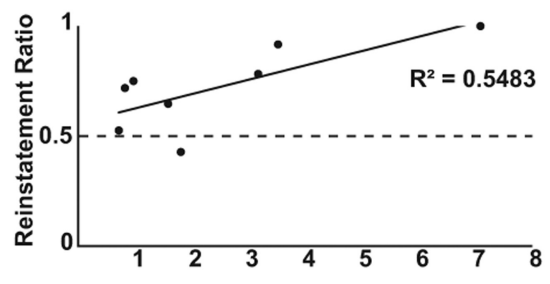

Aversive Events / Trial

Figure 3. The aversive drug cue causes drug seeking. $\boldsymbol{a}$, Lever pressing during self-administration and extinction. Session exts in paired $(n=8)$ and unpaired $(n=7)$ rats, mean + SE. $\boldsymbol{b}$, Paired rats showed more aversive taste respond morethan unpaired rats $(p<0.02)$. $\boldsymbol{d}$, The magnitude of the aversion caused by the drug cue predicted the reinstatement of drug seeking $(p<0.04)$. A ratio $>0.5$ (the horizontal dashed line) indicates an increase in responses on the tompared with extinction.

tration observed during the $5 \mathrm{~s}$ tone was compared with the peak DA observed in the final $5 \mathrm{~s}$ of the baseline epoch. Changes in DA were analyzed using repeated-measures ANOVAs and planned contrasts were used for direct comparisons.

Electrophysiology recording procedures. Subjects underwent electrode implantation surgery after their $15^{\text {th }}$ session of self-administration training. Recordings were conducted with microelectrode arrays featuring eight stainless steel wires (50 $\mu \mathrm{m}$ diameter) arranged in a $2 \times 4$ configuration (NB Labs). Following recovery, subjects received their final $3 \mathrm{~d}$ of self-administration and extinction. To familiarize the rats with the recording situation, they were connected to a flexible recording cable (Plexon) attached to a commutator (Crist Instruments) during these sessions. To assess encoding of the tone independent of lever pressing, eight paired and eight unpaired subjects also experienced noncontingent tone presentations during the last extinction session, and during the test session. Fifteen tone trials were delivered at $60 \mathrm{~s}$ intervals after the saccharin-infusion period. After the tone testing, the levers were extended, and extinction/reinstatement testing commenced. The headstage contained 16 miniature unity-gain field effect transistors. NAc activity was recorded differentially between each active wire and an inactive wire chosen for an absence of neuronal activity. Online isolation and discrimination were accomplished using a commercially available neurophysiological system (OmniPlex system; Plexon). Multiple-window discrimination modules and high-speed analog-to-digital signal processing in conjunction with computer software enabled isolation of neuronal signals based on waveform analysis. The neurophysiological system incorporated an array of digital signal processors (DSPs) for continuous spike recognition. The DSPs provided a continuous parallel digital output of neuronal events to a computer. Another computer controlled behavioral events of the experiment (Med Associates) and sent digital outputs corresponding to each event to the OmniPlex to be timestamped along with the neural data. Criteria for identifying different 


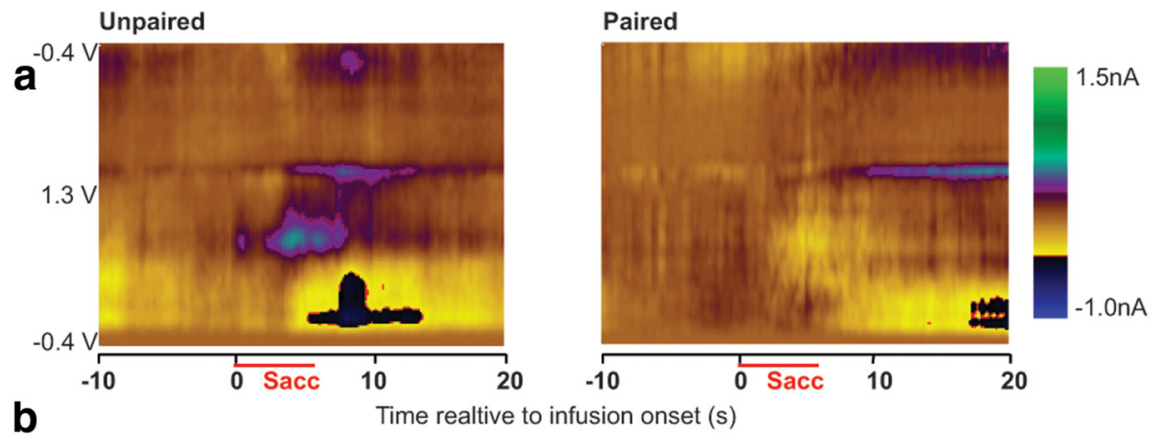

b

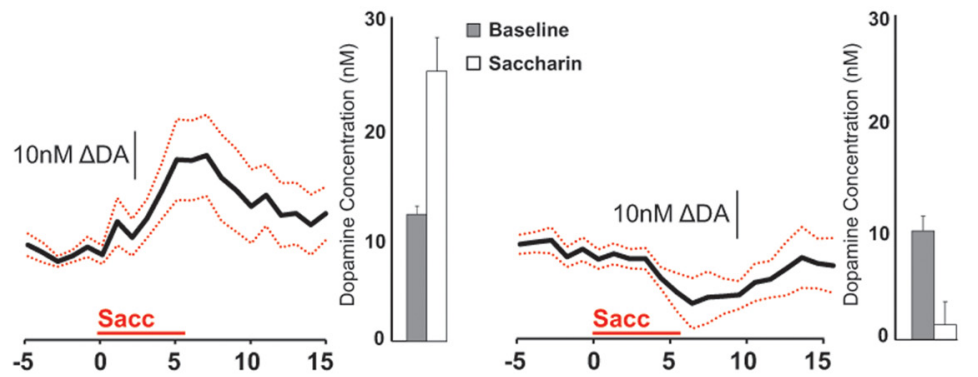

C
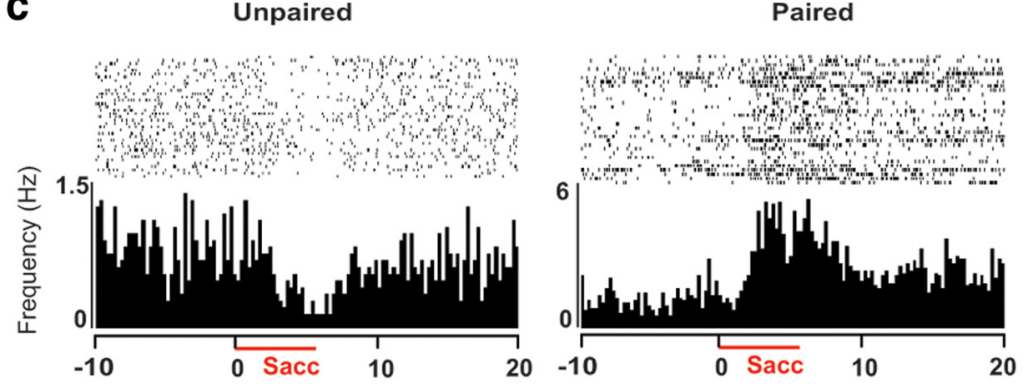

Time realtive to infusion onset (s)

d

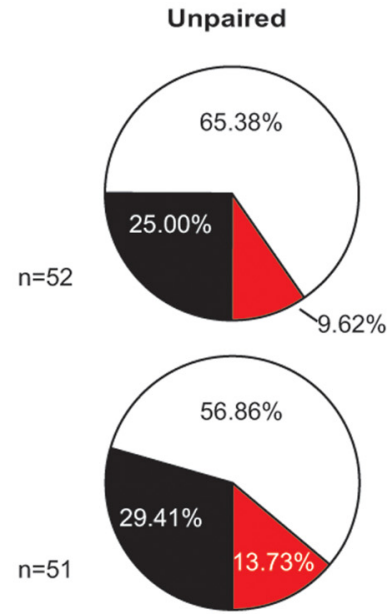

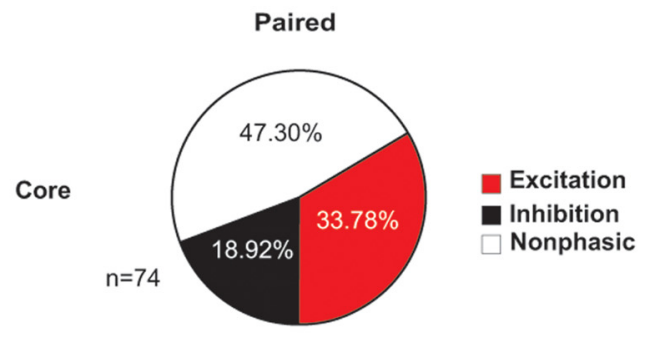

Shell

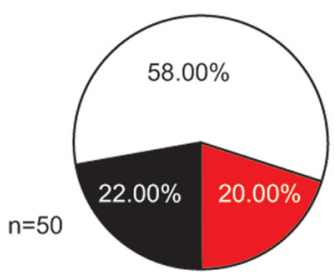

Figure 4. The aversive drug cue reduces DA and enhances neural excitation acutely. $\boldsymbol{a}$, Average color plots from representative unpaired (left) and paired (right) rats showing dopaminergic responses to saccharin (horizontal red line). The figures show current changes (nA; $z$-axis) plotted against voltage ( $V ; y$-axis) and time $(s ; x$-axis). $\boldsymbol{b}$, Relative to the 10 s baseline epoch, saccharin acutely increased DA concentration (nM) in unpaired rats (left) and decreased DA concentration in paired rats (right; $p<0.02$ ). Black lines show average concentration over time and red lines indicate SE for each group. Bars depict overall averages from the baseline and saccharin epochs. $c$, Rasters and histograms depict examples of inhibitory (left) and excitatory (right) changes in firing rate time-locked to the presentation of saccharin. Individual action potentials during each saccharin presentation are shown in the raster, and firing rate $(\mathrm{Hz})$ is shown in the histogram below. $\boldsymbol{d}$, Categorization of responses to saccharin in all recorded neurons. Unpaired neurons (left) show more excitatory than inhibitory responses to saccharin, whereas paired neurons (right) show more inhibitory than excitatory responses $(p<0.01)$.

neurons on a single wire were described previously in detail (Roitman et al., 2005). Briefly, discrimination of individual waveforms corresponding to a single neuron was accomplished using template and principle component analysis procedures provided by the PlexControl software sys- tem. The template analysis procedure involves taking a sample of the waveform and building a template of that extracellular waveform. Subsequent neurons that match this waveform are included as the same neuron. Cell sorting was further accomplished after the experiment was over using additional principle components analysis in Offline Sorter v3.3.2 (Plexon).

Phasic response categorization. Phasic encoding of the saccharin, tone, and lever-press response was characterized by generating peri-event histograms (500 ms bins) surrounding each event in Neuroexplorer 4.126 (Nex Technologies). To ensure a reliable histogram, lever-press responses were only considered whether the subject registered 10 or more responses spaced at least $20 \mathrm{~s}$ apart. Each histogram was divided into a baseline epoch and an effect epoch based on the type of event: (1) $10 \mathrm{~s}$ immediately following the onset of the saccharin infusion, (2) $5 \mathrm{~s}$ immediately following the onset of the tone, (3) $5 \mathrm{~s}$ immediately preceding a lever press, and (4) 5 s immediately following the lever press. Individual bins within the effect epochs were then standardized based on the mean and SD of the appropriate baseline epoch. Neurons that exhibited two or more bins with Z-scores that exceeded or fell $<3$ SD were classified as excitatory or inhibitory. Because some inhibitions reached $0 \mathrm{~Hz}$, but still did not fall below three Z-scores, inhibitory responses were also included if two or more bins had the minimum possible Z-score, provided that the effect epoch showed at least twice as many minimum bins as the baseline epoch. Neurons were also categorized based on a $t$ test comparison of the frequency bins of neurons that exhibited $>15 \%$ shifts in frequency from baseline to the effect epoch $(\alpha=0.05)$. After neurons were characterized, Fisher's exact tests were used to detect any differences in phasic responses and the distribution of excitatory and inhibitory responses in the core and shell during paired extinction, unpaired extinction, and paired testing.

Baseline analysis. An average firing rate $(\mathrm{Hz})$ for each trial was drawn from the baseline epoch for the saccharin infusion and transformed $\left[\log _{10}(x+0.001)\right]$ to normalize the distributions (Guillem et al., 2014). Trials were grouped in thirds to capture any changes in baseline firing that might occur during the saccharin period. Previously categorized tone and lever-press encoding neurons were selectively analyzed with repeatedmeasures ANOVAs to determine whether their baseline firing rates are altered during saccharin exposure. One inhibitory tone-encoding neuron in the unpaired group did not have sufficient data for a complete time course analysis.

Histology. After voltammetry and electrophysiology testing, subjects were killed with $\mathrm{CO}_{2}$. To verify placements of voltammetry recordings, small electrolytic lesions were created by running a current $(250 \mu \mathrm{A})$ through a stainless steel electrode placed at the depth at which the recording took place. Brains were then removed and submerged in $10 \%$ formaldehyde for $14 \mathrm{~d}$. For electrophysiology recordings, a current $(20 \mu \mathrm{A})$ was run through the implanted microwires, and brains incubated in a $10 \%$ formaldehyde/4\% potassium ferrocyanide solution. All brains were then sliced into $40 \mu \mathrm{m}$ sections, mounted, stained with 
$0.25 \%$ thionin, and coverslipped. Figure 2 shows the electrode placements from the voltammetry and electrophysiology experiments.

\section{Results}

The aversive drug cue reinstates extinguished drug seeking

Although prior studies have demonstrated a predictive relationship between cue-induced negative affect and drug taking, here we tested the ability of an aversive drug cue to cause reinstatement. Because self-administration sessions had a quota/ cap, all subjects took the same amount of cocaine. To examine the extinction data (Fig. 3a), responses on the formerly active lever (excluding those made during the time out period) were analyzed. Both groups decreased responding similarly on the active lever across sessions (session: $F_{(4,52)}=$ $22.41, p<0.01$; all other $p$ values $>0.19$ ).

Taste reactivity to saccharin at test resembled previous reports (Fig. 3b), with paired rats showing more aversive $(p<$ $0.02)$ and fewer appetitive $(p<0.01)$ responses relative to unpaired rats (group $\times$ taste reactivity: $F_{(1,13)}=25.75, p<0.01$; all other $p$ values $>0.45)$. Paired rats exhibited enhanced drug seeking relative to their final extinction session (Fig. $3 c ; t_{(7)}=3.85, p<$ $0.01)$, and unpaired rats at test $\left(t_{(13)}=2.90\right.$, $p<0.02$ ). In contrast, responses on the inactive lever did not differ between paired (mean $=2.88 ; \mathrm{SE}=1.08)$ and unpaired rats $\left(\right.$ mean $=2.88 ; \mathrm{SE}=1.08 ; t_{(13)}=1.68, p=$ $0.12)$. Furthermore, the aversive reaction to cocaine-associated saccharin was correlated with reinstatement in paired rats (Fig. $3 d$; $\left.r_{(6)}=0.74, p<0.04\right)$.

The aversive drug cue reduces DA and enhances neural excitation acutely Consistent with observations in the NAcS (Wheeler et al., 2011), the aversive and appetitive stimuli had opposite effects on NAcC DA (Fig. 4a,b). Cocaine-predictive saccharin caused an acute decrease in NAc DA concentration in the paired group, whereas appetitive unpaired saccharin caused an acute increase in DA concentration (group $\times$ epoch: $F_{(1,6)}=10.45, p<$ 0.02; group: $F_{(1,6)}=6.42, p<0.01$; epoch: $p>0.50)$.

Also consistent with prior reports, aversive and appetitive stimuli had differential effects on NAc neuronal firing rates. Figure $4 c$ shows examples of inhibitory and excitatory neural encoding of the saccharin stimulus at test. Saccharin infusions were encoded by $48.39 \%(n=60 / 124)$ of the paired neurons and $38.84 \%$ of the unpaired neurons ( $n=40 / 103)$. Encoding of the aversive drug cue was predominantly excit- a

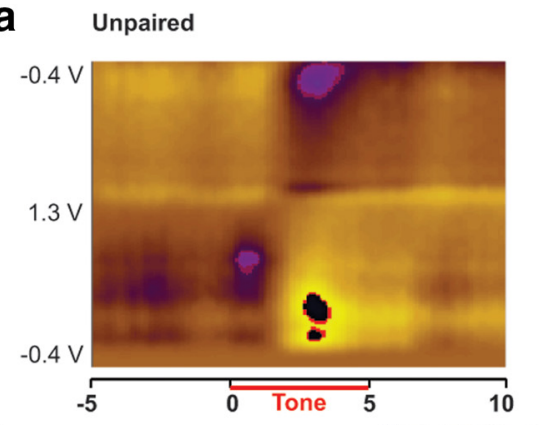

Paired

b
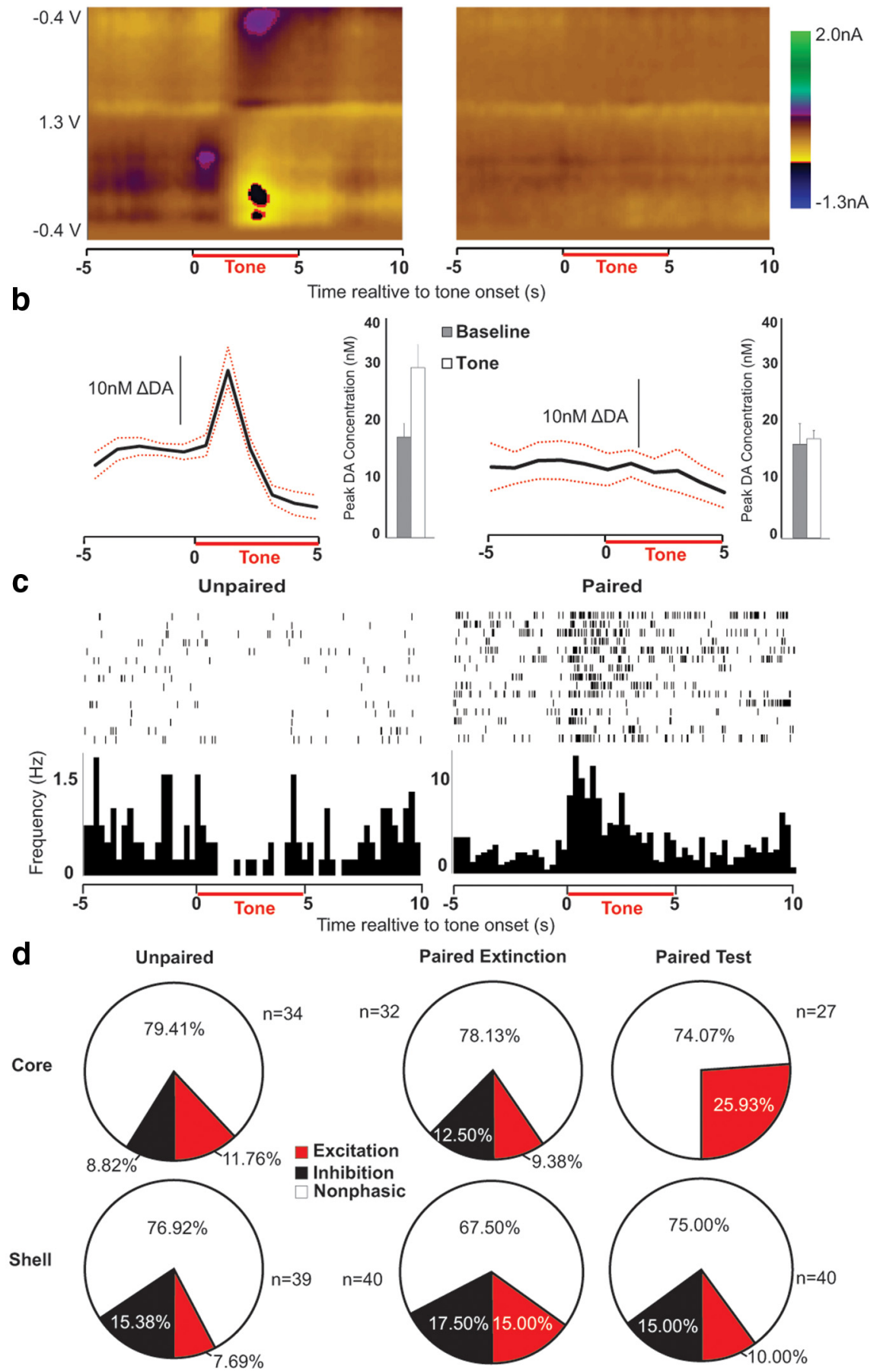

Figure 5. The aversive drug cue eliminates DA encoding and augments excitatory neural encoding of the proximate drug cue. $\boldsymbol{a}$, Average color plots from a representative unpaired (left) and paired (right) rat showing the dopaminergic response to the proximate drug cue (tone; horizontal red line). The figures show current changes ( $\mathrm{nA} ; z$-axis) plotted against voltage $(\mathrm{V} ; y$-axis) and time $(s ; x$-axis). $\boldsymbol{b}$, Relative to the $5 \mathrm{~s}$ baseline epoch, the tone caused a brief increase in DA concentration (nм) in unpaired rats $(p<0.01)$, and this response was abolished by the preceding experience of the aversive drug cue in paired rats $(p=0.70)$. Black lines show average concentration over time and red lines indicate SE for each group. Bars depict average peak DA from the baseline and tone epochs. $c$, Rasters and histograms depict examples of inhibitory (left) and excitatory (right) neural encoding of the tone. Individual action potentials during each tone presentation are shown in the raster, and firing rate $(\mathrm{Hz})$ is shown in the histogram below. $\boldsymbol{d}$, Categorization of responses to the tone in all recorded neurons. Paired neurons (right) show more excitatory encoding in the core relative to the shell at test $(p<0.04)$, but this difference in excitatory encoding was not apparent in paired neurons during extinction (center; $p=0.63$ ) or in unpaired neurons (left; $p=0.62$ ). 
a

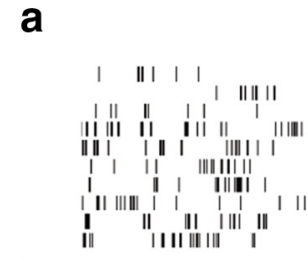

$\downarrow$

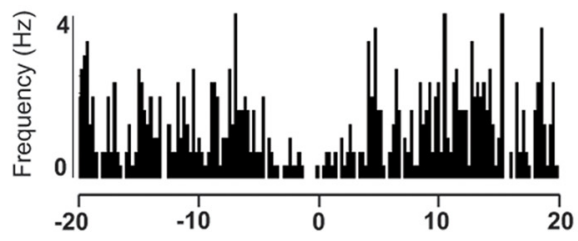

Time relative to lever press (s)

\section{b}
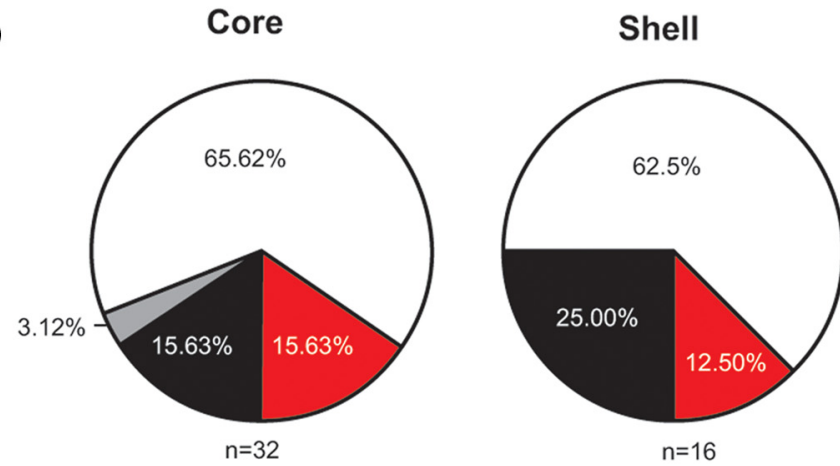

Figure 6. NAc neurons encode responses during reinstatement of cocaine seeking. $\boldsymbol{a}$, Representative inhibitory (left) and excitatory (right) encoding of lever press at test. Individual action potentials aligned to each lever press (red arrows) are shown in the raster, and firing rate $(\mathrm{Hz})$ is shown in the histogram below. $\boldsymbol{b}$, Categorization of lever-press encoding in paired neurons at test.

atory in nature $(n=35 / 60)$ rather than inhibitory $(n=25 / 60)$. This ratio was reversed $(p<0.01)$ in the unpaired group, in which encoding was predominantly inhibitory $(n=28 / 40)$ rather than excitatory $(n=12 / 40)$. Figure $4 d$ depicts the proportion of responsive neurons in each subregion.

The aversive drug cue eliminates DA encoding of the extinguished proximate drug cue

The tone was presented after saccharin exposure to determine whether reinstatement behavior co-occurs with renewed DA encoding of the extinguished proximate drug cue. The results revealed the opposite (Fig. $5 a, b$; group $\times$ epoch: $F_{(1,6)}=6.30, p<$ $0.05)$. The proximate drug cue caused a rapid, transient increase in DA in the unpaired group $(p<0.01)$, but this DA response was not observed in the paired group $(p>0.70)$. Surprisingly, these data suggest that dampened dopamine signaling caused by aversive cocaine-predictive saccharin persists during the time in which an animal transitions to drug seeking and diminishes the dopaminergic encoding of other drug predictive cues.

The aversive drug cue augments excitatory neural encoding of the extinguished proximate drug cue

Considering the suppression of DA encoding of the tone in the paired group, the neural encoding of this stimulus was of particular interest. The tone was encoded by $27.78 \%(n=20 / 72)$ of paired neurons on the last day of extinction and $25.37 \%(n=$ $17 / 67)$ of paired neurons at test. In the unpaired group, $22.0 \%$ $(n=16 / 73)$ of neurons encoded the tone at test, indicating no effect of group or treatment on the overall proportion of tone-encoding neurons in the NAc $(p>0.40)$. However, the nature of these phasically active neurons (excitations or inhibi- $\square$ Excitation

- Inhibition

$\square$ Multiphasic

$\square$ Nonphasic

tions) varied based on the treatment and brain region (Fig. $5 c, d$ ). Tone-encoding neuronal responses were roughly evenly distributed between excitations and inhibitions in the unpaired condition (excitation/inhibition ratio: core, $n=4 / 3$; shell, $n=3 / 6 ; p=0.62$ ), as well as the paired condition during extinction (core, $n=$ 3/4; shell, $n=6 / 7 ; p=0.63$ ). However, the presence of the aversive, drug predictive cue induced a significant shift toward excitatory responses in the NAcC in the paired group at test $(n=7 / 0)$ relative to the NAcS $(n=4 / 6 ; p<0.04)$. Thus, a shift toward excitatory encoding co-occurred with the suppression of DA encoding.

The examination of neural encoding of drug-seeking was restricted to rats that registered enough lever presses to produce a reliable histogram, which limited the analysis to rats in the paired group at test $(n=5)$. Overall, $34.38 \%(n=11 / 32)$ NAcC and $37.5 \%(n=6 / 16)$ NAcS neurons encoded one or more aspects (preand/or postresponse) of the lever-press behavior. Of the phasically active NAcC neurons, 54.55\% $(n=6 / 11)$ exhibited some form of excitatory encoding, and $54.55 \%(n=6 / 11)$ exhibited inhibitory encoding ( 1 neuron exhibited a phasic decrease before and a phasic increase after the response), whereas NAcS neuronal responses were $33.33 \%(n=2 / 6)$ excitatory and $66.67 \%(n=4 / 6)$ inhibitory (Fig. $6 a, b)$.

The aversive drug cue reduces baseline DA and enhances the baseline excitability of neurons that will encode future drugseeking behavior

In the NAcS, an aversive drug cue causes a long term, diffuse depression of DA concentration, as well as an acute time-locked DA decrease (Wheeler et al., 2011). The presence of the diffuse depression might be especially important for reinstatement of drug seeking (Twining et al., 2014). We tested for the presence of this phenomenon here by performing an analysis of baseline (10 $s$ preinfusion) DA concentration in the NAcC across trials during the saccharin exposure period (Fig. 7a). The baseline period was blocked into early and late session DA concentration. One subject in the paired group lacked sufficient data to construct a complete time course and could not be included in this analysis, but it was clear that baseline DA concentration changed in a non-timelocked manner across trials differentially depending on group (Fig. $7 c$; group $\times$ trial block: $F_{(1,5)}=22.39, p<0.01$; all other $p$ values $>0.20)$. Planned comparisons revealed that appetitive, unpaired saccharin increased basal DA concentration across trials $(p<$ 0.02 ), and aversive, cocaine-predictive saccharin decreased basal DA concentration across trials $(p<0.03)$.

Because fluctuations in DA can modulate neural excitability (Surmeier et al., 2007), we were interested in how diffuse changes in DA might relate to the baseline excitability of NAc neurons. Furthermore, we isolated neurons that would later go on to encode the proximate drug cue or drug-seeking behavior in the next phase of testing to determine whether paired saccharin differentially impacted the behavior of these neurons (Fig. 7b). Because of 
the limited number of previously categorized neurons, both categories of responses (inhibitory and excitatory) were combined for this analysis. Changes in baseline firing rates were assessed by blocking the saccharin period into thirds and generating three average baseline firing rate measurements for each neuron. An ANOVA revealed a significant interaction between all factors (trial block $\times$ group $\times$ subregion: $F_{(2,56)}=4.20, p=$ $0.02)$ and a marginal interaction between group and trial block $\left(F_{(1,25)}=3.87, p=\right.$ $0.05)$ but no other effects $(p>0.17)$. A post hoc analysis showed that the aversive cocaine cue caused an increase in the baseline firing rates from the beginning to the end of the saccharin period specifically in NAcC neurons that would later encode the tone cue (Fig. $7 d ; p<0.05$; all other $p$ values $>0.80)$. Notably, all of the paired core neurons that increased their baseline firing rates were recorded in subjects that exhibited reinstatement (reinstatement ratios $>0.50$ ), whereas the single neuron that did not increase firing rate across the saccharin session was recorded in a subject that did not show appreciable aversive taste reactivity $(<0.50$ aversive events/ trial) or reinstatement.

Similar to tone-encoding neurons in the core, neurons that encoded drug seeking exhibited a change in baseline activity during exposure to the aversive saccharin stimulus (Fig. 7e). In this case, baseline firing rates in both the core and shell neurons increased during the saccharin period $\left(F_{(2,18)}=4.51, p<0.03\right.$; all other $p$ values $>0.09)$. Importantly, an analysis of all neurons (including nonencoding neurons) showed that most baseline firing rates decreased during the saccharin period regardless of group (Fig. $7 f ; F_{(2,420)}=$ 4.88, $p<0.01$ ), and baseline activity in the paired group was generally higher than the unpaired group $\left(F_{(1,210)}=7.37, p<\right.$ 0.01 ; all other $p$ values $>0.07)$. Considering the general downward trend in baseline activity, the increase in firing rate in neurons that encode drug seeking or the proximate drug cue is exceptional.

\section{Discussion}

The present findings show that a natural reward that signals delayed access to cocaine becomes aversive and reinstates drug seeking after extinction. The presence of this aversive drug cue decreases acute and diffuse DA release in the NAcC and increases the baseline firing rates of neurons that will subsequently encode the proximate cocaine cue and cocaineseeking behavior. Furthermore, the aversive drug cue also eliminates the dopaminergic encoding of the proximate drug cue. This demonstrates a pronounced depression of DA signaling that persists long after the aversive drug cue is removed. At the same time, excitatory encoding of the proximate cue is enhanced specifically in the NAcC. This relationship between b

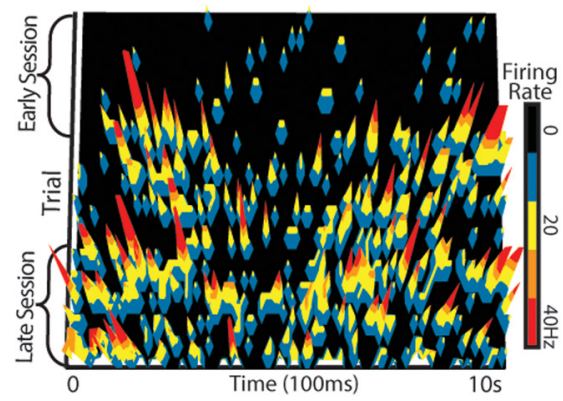

d

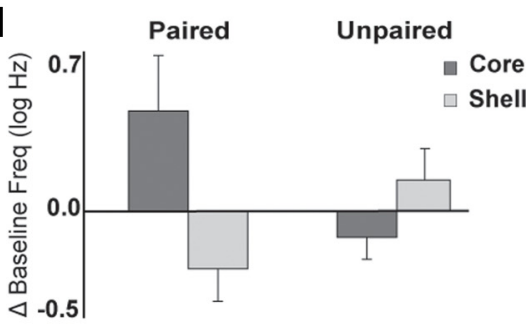

f

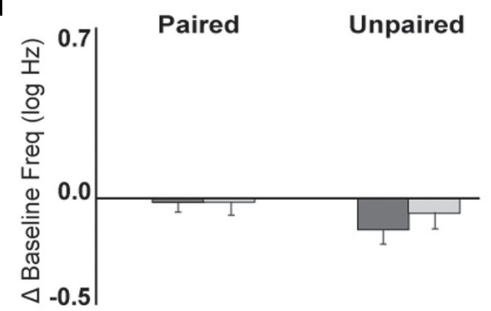

Figure 7. The aversive drug cue reduces DA and enhances excitability of neurons that will encode future drug-seeking behavior. $\boldsymbol{a}$, Baseline DA (nм; $z$-axis) across trials ( $y$-axis) throughout the saccharin period in a representative paired rat. $\boldsymbol{b}$, Baseline firing De 政 政 $(p<0.03) . f$, The change in baseline firing rates in all recorded units before saccharin infusion in paired and unpaired rats. Saccharin reduced baseline firing rates in the full population of recorded neurons $(p<0.01)$.

dampened DA signaling and enhanced neural excitability provides insight into how negative affect can drive compensatory drug-seeking behavior.

\section{Behavioral design}

The present design differs from studies of noncontingent drug cue- and context-induced reinstatement (Crombag and Shaham, 2002; Saunders et al., 2013) because it allows for direct assessment of the affective state of the animal during cue exposure. It differs from cue-induced reinstatement designs in which subjects receive response-contingent presentations of an unextinguished drug cue (Davis and Smith, 1976) because it is not directly driven by the conditioned incentive value of the saccharin cue (which is presumably punishing). As such, it is capable of providing unique insight to the physiological mechanisms underlying the induction of negative affect by drug cues, and is useful for modeling cue-induced changes in affective state that may promote relapse in human addicts.

The present design resembles other context-induced reinstatement models in that the extinction context (unpaired saccharin in our design) could be an omission cue. Thus, the critical 
behavioral and physiological differences between the groups could be due to the presence of an omission signal suppressing behavior in the unpaired group, rather than the presence of an aversive drug cue in the paired group inducing behavior. Several observations make this unlikely. First, both groups extinguished at the same rate, suggesting that the unpaired cue was not being used as an omission signal to guide behavior. Also, electrophysiological responses to the tone did not differ during extinction in the paired and unpaired groups, indicating that the presence of a potential omission signal did not influence encoding of the proximate cue. Finally, recent findings indicate that the presence of an innately aversive taste stimulus is sufficient to cause drug seeking. We observed a similar level of reinstatement following exposure to quinine, an inherently aversive stimulus that had no association with drug access (Twining et al., 2014). Similarly, in the present study the magnitude of the reinstatement effect was positively correlated with the expression of aversion. Together these observations indicate that it is the aversive status of the cocaine cue, and the negative affect and neurochemical environment that it engenders, that induce drug seeking.

\section{The impact of an aversive drug cue on DA encoding of a} proximate drug cue

The observation of persistent dopaminergic encoding of an extinguished drug cue in the unpaired group may be surprising, but it is consistent with contemporary theory regarding the product of extinction. Extinction produces suppression of behavior, but without direct physiological intervention (Lee et al., 2006; Otis et al., 2013) or perhaps precise timing (Monfils et al., 2009), it does not result in a loss of learning (Bouton, 2004; Miller and Matzel, 2006). Neural processing of an extinguished drug cue is an interaction between memories of reinforcement and nonreinforcement, and the DA response likely reflects this ambiguity. As such, it is not surprising that brain chemistry is more reactive to an extinguished drug cue than a nonassociated behaviorally inert stimulus, which does not typically elevate NAc DA (Phillips et al., 2003).

The fact that reinstatement behavior was accompanied by a suppression of the dopaminergic encoding of a proximate drugcue was surprising. Even so, the present result is more intuitive when informed by observations of DA signaling during cocaine self-administration. For example, rats that exhibit escalated drug use actually show attenuated DA encoding of drug-taking behavior (Willuhn et al., 2014). Furthermore, drug taking is reduced when positive DA encoding is restored through pharmacological intervention. That is, rats seek more cocaine because DA encoding is depressed, and reduce responding when it is restored (Willuhn et al., 2014). In this light, it is provocative to consider the possibility that if the acute DA elevation mediates the suppression of drug taking, then it is possible that positive DA signaling also works to suppress drug seeking after extinction. The aversive drug cue may spur behavior, in part by eliminating this neurochemical event. This explanation is consistent with the observation that vigorous cocaine seeking/taking behavior tends to be preceded by reductions in NAc DA (Wise et al., 1995; Tsibulsky and Norman, 1999; Stuber et al., 2005).

In contrast to the present results, it is important to recognize that some aversive stimuli can increase DA and reinstate drug seeking. For example, electric footshock increases NAc DA as measured by microdialysis, and this increase in DA is sustained as drug seeking is reinstated (McFarland et al., 2004). There are many factors that may contribute to this discrepancy (Wenzel et al., 2015). The nociceptive stimulation produced by electrical footshock is typically very brief, discrete, and naturally engages robust locomotor behaviors that facilitate escape from the experimental context. In contrast, the taste infusions used here are relatively long, occur over an extended period of time, and induce behaviors of gustatory rejection that involve little locomotion (culminating with passive rejection). It is noteworthy that aversive gustatory stimuli can elevate DA in the NAcC (Bassareo et al., 2002), indicating that modality is not the only critical factor. Regardless of the root cause(s) of this discrepancy, it is important to examine these different situations because both can lead to enhanced drug seeking, and may do so through dissociable mechanisms.

\section{The role of NAc neural and neurochemical signaling in drug} seeking

Broadly, activity in the NAc mediates reinstatement phenomena (Bossert et al., 2013). Disrupting activity in the NAc attenuates stress-, cue-, cocaine-, and context-induced reinstatement (Cornish and Kalivas, 2000; Fuchs et al., 2004, 2008; McFarland et al., 2004; Xie et al., 2012). Specifically, corticostriatal glutamatergic projections drive relapse phenomena (McFarland et al., 2003, 2004; Stefanik et al., 2013). In the present experiments, reinstatement was associated with enhanced excitability in two ways. First, exposure to the aversive drug cue elevated the baseline excitatory activity of neurons that would eventually encode the proximate drug cue and/or drug-seeking behavior. This observation reveals a physiological mechanism that directly connects cue-induced negative affect to the subsequent drug-seeking act. Second, the aversive drug cue caused drug seeking and enhanced excitatory encoding of the proximate drug cue. This change in cue reactivity could contribute to the reinstated drug seeking observed here and in studies that show behavioral synergy between aversive stimuli and proximate drug cues (Liu and Weiss, 2002; Buffalari and See, 2009), even if the proximate drug cue has been extinguished (Shelton and Beardsley, 2005).

\section{The relationship between decreased DA signaling and a shift toward excitatory activity}

The effect of DA on striatal neural activity is complex and depends on a number of factors, such as D1-like and D2-like receptor expression, as well as the collateral influence of DA-sensitive interneurons (Surmeier et al., 2007). In general, D1-like receptor activation enhances excitability (Surmeier et al., 1995), appetitive stimuli preferentially activate D1-expressing neurons (Xiu et al., 2014), and excitatory encoding of motivated behavior coincides with and is sometimes contingent upon elevated DA signaling in the NAc (Owesson-White et al., 2009; Cacciapaglia et al., 2011). In contrast, D2-like receptor activation inhibits neuron excitability (Hernandez-Lopez et al., 2000), D2-expressing neurons are preferentially activated by aversive stimuli (Xiu et al., 2014), and acute inhibition of DA signaling induces aversion by activating D2-expressing neurons in the NAc (Danjo et al., 2014). Given our coincident observations of decreased dopamine signaling, increased NAc activity, and behavioral signs of negative affect, we hypothesize that the current results reflect a disinhibited D2mediated aversion-sensitive striatal circuit.

The product of aversion-induced neural activation has been linked to behavioral inhibition (i.e., no-go; Nakanishi et al., 2014), but activation of D2-like-expressing neurons is also important for directing new behaviors that avoid aversive outcomes (Mehta et al., 2001; Yawata et al., 2012; Porter-Stransky et al., 2013). This convergent evidence strongly suggests that cue- and aversion-induced reductions in DA signaling play a critical role in enhancing the excitability of neurons that encode proximate drug 
cues and drug-seeking behavior. The interaction between negative affect, dampened DA signaling, and enhanced neural excitability highlights a physiological substrate by which negative reinforcement mechanisms can augment cue reactivity and drive behavior. This aversion-driven behavioral modulation could be directed toward escape in adaptive behavioral contexts, but in a drug-seeking context, it may promote drug seeking in an effort to correct the negative affective state. Future experiments will be needed to investigate the precise causal role of physiologically relevant DA reductions in initiating this maladaptive cascade of events.

\section{References}

Baker TB, Piper ME, McCarthy DE, Majeskie MR, Fiore MC (2004) Addiction motivation reformulated: an affective processing model of negative reinforcement. Psychol Rev 111:33-51. CrossRef Medline

Bassareo V, De Luca MA, Di Chiara G (2002) Differential expression of motivational stimulus properties by dopamine in nucleus accumbens shell versus core and prefrontal cortex. J Neurosci 22:4709-4719. Medline

Bossert JM, Marchant NJ, Calu DJ, Shaham Y (2013) The reinstatement model of drug relapse: recent neurobiological findings, emerging research topics, and translational research. Psychopharmacology (Berl) 229:453476. CrossRef Medline

Bouton ME (2004) Context and behavioral processes in extinction. Learn Mem 11:485-494. CrossRef Medline

Buffalari DM, See RE (2009) Footshock stress potentiates cue-induced cocaine-seeking in an animal model of relapse. Physiol Behav 98:614617. CrossRef Medline

Cacciapaglia F, Wightman RM, Carelli RM (2011) Rapid dopamine signaling differentially modulates distinct microcircuits within the nucleus accumbens during sucrose-directed behavior. J Neurosci 31:13860-13869. CrossRef Medline

Childress AR, Mozley PD, McElgin W, Fitzgerald J, Reivich M, O'Brien CP (1999) Limbic activation during cue-induced cocaine craving. Am J Psychiatry 156:11-18. CrossRef Medline

Colechio EM, Imperio CG, Grigson PS (2014) Once is too much: conditioned aversion develops immediately and predicts future cocaine selfadministration behavior in rats. Behav Neurosci 128:207-216. CrossRef Medline

Cornish JL, Kalivas PW (2000) Glutamate transmission in the nucleus accumbens mediates relapse in cocaine addiction. J Neurosci 20:RC89. Medline

Crombag HS, Shaham Y (2002) Renewal of drug seeking by contextual cues after prolonged extinction in rats. Behav Neurosci 116:169-173. CrossRef Medline

Danjo T, Yoshimi K, Funabiki K, Yawata S, Nakanishi S (2014) Aversive behavior induced by optogenetic inactivation of ventral tegmental area dopamine neurons is mediated by dopamine $\mathrm{D} 2$ receptors in the nucleus accumbens. Proc Natl Acad Sci U S A 111:6455-6460. CrossRef Medline

Davis WM, Smith SG (1976) Role of conditioned reinforcers in the initiation, maintenance and extinction of drug-seeking behavior. Pavlov J Biol Sci 11:222-236. Medline

Di Chiara G (1999) Drug addiction as dopamine-dependent associative learning disorder. Eur J Pharmacol 375:13-30. CrossRef Medline

Everitt BJ, Belin D, Economidou D, Pelloux Y, Dalley JW, Robbins TW (2008) Neural mechanisms underlying the vulnerability to develop compulsive drug-seeking habits and addiction. Philos Trans R Soc Lond B Biol Sci 363:3125-3135. CrossRef Medline

Fuchs RA, Evans KA, Parker MC, See RE (2004) Differential involvement of the core and shell subregions of the nucleus accumbens in conditioned cue-induced reinstatement of cocaine seeking in rats. Psychopharmacology (Berl) 176:459-465. CrossRef Medline

Fuchs RA, Ramirez DR, Bell GH (2008) Nucleus accumbens shell and core involvement in drug context-induced reinstatement of cocaine seeking in rats. Psychopharmacology (Berl) 200:545-556. CrossRef Medline

Garavan H, Pankiewicz J, Bloom A, Cho JK, Sperry L, Ross TJ, Salmeron BJ, Risinger R, Kelley D, Stein EA (2000) Cue-induced cocaine craving: neuroanatomical specificity for drug users and drug stimuli. Am J Psychiat 157:1789-1798. CrossRef Medline

Grigson PS, Twining RC (2002) Cocaine-induced suppression of saccharin intake: a model of drug-induced devaluation of natural rewards. Behav Neurosci 116:321-333. CrossRef Medline

Grill HJ, Norgren R (1978) The taste reactivity test: I. Mimetic responses to gustatory stimuli in neurologically normal rats. Brain Res 143:263-279. CrossRef Medline

Guillem K, Ahmed SH, Peoples LL (2014) Escalation of cocaine intake and incubation of cocaine seeking are correlated with dissociable neuronal processes in different accumbens subregions. Biol Psychiatry 76:31-39. CrossRef Medline

Heien ML, Johnson MA, Wightman RM (2004) Resolving neurotransmitters detected by fast-scan cyclic voltammetry. Anal Chem 76:5697-5704. CrossRef Medline

Heien ML, Khan AS, Ariansen JL, Cheer JF, Phillips PE, Wassum KM, Wightman RM (2005) Real-time measurement of dopamine fluctuations after cocaine in the brain of behaving rats. Proc Natl Acad Sci U S A 102:1002310028. CrossRef Medline

Hernandez-Lopez S, Tkatch T, Perez-Garci E, Galarraga E, Bargas J, Hamm H, Surmeier DJ (2000) D2 dopamine receptors in striatal medium spiny neurons reduce L-type $\mathrm{Ca} 2+$ currents and excitability via a novel PLC[beta] 1-IP3-calcineurin-signaling cascade. J Neurosci 20:8987-8995. Medline

Hollander JA, Carelli RM (2007) Cocaine-associated stimuli increase cocaine seeking and activate accumbens core neurons after abstinence. J Neurosci 27:3535-3539. CrossRef Medline

Koob GF, Le Moal M (2008) Addiction and the brain antireward system. Annu Rev Psychol 59:29-53. CrossRef Medline

Lee JL, Milton AL, Everitt BJ (2006) Cue-induced cocaine seeking and relapse are reduced by disruption of drug memory reconsolidation. J Neurosci 26:5881-5887. CrossRef Medline

Liu X, Weiss F (2002) Additive effect of stress and drug cues on reinstatement of ethanol seeking: exacerbation by history of dependence and role of concurrent activation of corticotropin-releasing factor and opioid mechanisms. J Neurosci 22:7856-7861. Medline

McFarland K, Lapish CC, Kalivas PW (2003) Prefrontal glutamate release into the core of the nucleus accumbens mediates cocaine-induced reinstatement of drug-seeking behavior. J Neurosci 23:3531-3537. Medline

McFarland K, Davidge SB, Lapish CC, Kalivas PW (2004) Limbic and motor circuitry underlying footshock-induced reinstatement of cocaine-seeking behavior. J Neurosci 24:1551-1560. CrossRef Medline

Mehta MA, Swainson R, Ogilvie AD, Sahakian J, Robbins TW (2001) Improved short-term spatial memory but impaired reversal learning following the dopamine $\mathrm{D}(2)$ agonist bromocriptine in human volunteers. Psychopharmacology (Berl) 159:10-20. CrossRef Medline

Miller RR, Matzel LD (2006) Retrieval failure versus memory loss in experimental amnesia: definitions and processes. Learn Mem 13:491-497. CrossRef Medline

Monfils MH, Cowansage KK, Klann E, LeDoux JE (2009) Extinctionreconsolidation boundaries: key to persistent attenuation of fear memories. Science 324:951-955. CrossRef Medline

Nakanishi S, Hikida T, Yawata S (2014) Distinct dopaminergic control of the direct and indirect pathways in reward-based and avoidance learning behaviors. Neuroscience 282C:49-59. CrossRef Medline

Nyland JE, Grigson PS (2013) A drug-paired taste cue elicits withdrawal and predicts cocaine self-administration. Behav Brain Res 240:87-90. CrossRef Medline

Otis JM, Dashew KB, Mueller D (2013) Neurobiological dissociation of retrieval and reconsolidation of cocaine-associated memory. J Neurosci 33:1271-1281. CrossRef Medline

Owesson-White CA, Ariansen J, Stuber GD, Cleaveland NA, Cheer JF, Wightman RM, Carelli RM (2009) Neural encoding of cocaine-seeking behavior is coincident with phasic dopamine release in the accumbens core and shell. Eur J Neurosci 30:1117-1127. CrossRef Medline

Phillips PE, Stuber GD, Heien ML, Wightman RM, Carelli RM (2003) Subsecond dopamine release promotes cocaine seeking. Nature 422:614618. CrossRef Medline

Porter-Stransky KA, Seiler JL, Day JJ, Aragona BJ (2013) Development of behavioral preferences for the optimal choice following unexpected reward omission is mediated by a reduction of D2-like receptor tone in the nucleus accumbens. Eur J Neurosci 38:2572-2588. CrossRef Medline

Robinson TE, Berridge KC (2003) Addiction. Annu Rev Psychol 54:25-53. CrossRef Medline

Roitman MF, Wheeler RA, Carelli RM (2005) Nucleus accumbens neurons are innately tuned for rewarding and aversive taste stimuli, encode their 
predictors, and are linked to motor output. Neuron 45:587-597. CrossRef Medline

Roitman MF, Wheeler RA, Wightman RM, Carelli RM (2008) Real-time chemical responses in the nucleus accumbens differentiate rewarding and aversive stimuli. Nat Neurosci 11:1376-1377. CrossRef Medline

Saunders BT, Yager LM, Robinson TE (2013) Cue-evoked cocaine "craving": role of dopamine in the accumbens core. J Neurosci 33:1398914000. CrossRef Medline

Shaham Y, Shalev U, Lu L, De Wit H, Stewart J (2003) The reinstatement model of drug relapse: history, methodology and major findings. Psychopharmacology (Berl) 168:3-20. CrossRef Medline

Shelton KL, Beardsley PM (2005) Interaction of extinguished cocaineconditioned stimuli and footshock on reinstatement in rats. Int J Comp Psychol 18:154-166.

Sinha R, Fuse T, Aubin LR, O’Malley SS (2000) Psychological stress, drugrelated cues and cocaine craving. Psychopharmacology (Berl) 152:140148. CrossRef Medline

Sinha R, Talih M, Malison R, Cooney N, Anderson GM, Kreek MJ (2003) Hypothalamic-pituitary-adrenal axis and sympatho-adreno-medullary responses during stress-induced and drug cue-induced cocaine craving states. Psychopharmacology (Berl) 170:62-72. CrossRef Medline

Stefanik MT, Moussawi K, Kupchik YM, Smith KC, Miller RL, Huff ML, Deisseroth K, Kalivas PW, LaLumiere RT (2013) Optogenetic inhibition of cocaine seeking in rats. Addict Biol 18:50-53. CrossRef Medline

Stuber GD, Wightman RM, Carelli RM (2005) Extinction of cocaine selfadministration reveals functionally and temporally distinct dopaminergic signals in the nucleus accumbens. Neuron 46:661-669. CrossRef Medline

Surmeier DJ, Bargas J, Hemmings HC Jr, Nairn AC, Greengard P (1995) Modulation of calcium currents by a D1 dopaminergic protein kinase/ phosphatase cascade in rat neostriatal neurons. Neuron 14:385-397. CrossRef Medline

Surmeier DJ, Ding J, Day M, Wang Z, Shen W (2007) D1 and D2 dopaminereceptor modulation of striatal glutamatergic signaling in striatal medium spiny neurons. Trends Neurosci 30:228-235. CrossRef Medline

Tsibulsky VL, Norman AB (1999) Satiety threshold: a quantitative model of maintained cocaine self-administration. Brain Res 839:85-93. CrossRef Medline
Twining RC, Wheeler DS, Ebben AL, Jacobsen AJ, Robble MA, Mantsch JR, Wheeler RA (2014) Aversive stimuli drive drug seeking in a state of low dopamine tone. Biol Psychiatry. Advance online publication. CrossRef Medline

Tzschentke TM (1998) Measuring reward with the conditioned place preference paradigm: a comprehensive review of drug effects, recent progress and new issues. Prog Neurobiol 56:613-672. CrossRef Medline

Wenzel JM, Rauscher NA, Cheer JF, Oleson EB (2015) A role for phasic dopamine release within the nucleus accumbens in encoding aversion: a review of the neurochemical literature. ACS Chem Neurosci 6:16-26. CrossRef Medline

Wheeler RA, Twining RC, Jones JL, Slater JM, Grigson PS, Carelli RM (2008) Behavioral and electrophysiological indices of negative affect predict cocaine self-administration. Neuron 57:774-785. CrossRef Medline

Wheeler RA, Aragona BJ, Fuhrmann KA, Jones JL, Day JJ, Cacciapaglia F, Wightman RM, Carelli RM (2011) Cocaine cues drive opposing context-dependent shifts in reward processing and emotional state. Biol Psychiatry 69:1067-1074. CrossRef Medline

Willuhn I, Burgeno LM, Groblewski PA, Phillips PE (2014) Excessive cocaine use results from decreased phasic dopamine signaling in the striatum. Nat Neurosci 17:704-709. CrossRef Medline

Wise RA, Newton P, Leeb K, Burnette B, Pocock D, Justice JB Jr (1995) Fluctuations in nucleus-accumbens dopamine concentration during intravenous cocaine self-administration in rats. Psychopharmacology 120: 10-20. CrossRef Medline

Xie X, Lasseter HC, Ramirez DR, Ponds KL, Wells AM, Fuchs RA (2012) Subregion-specific role of glutamate receptors in the nucleus accumbens on drug context-induced reinstatement of cocaine-seeking behavior in rats. Addict Biol 17:287-299. CrossRef Medline

Xiu J, Zhang Q, Zhou T, Zhou TT, Chen Y, Hu H (2014) Visualizing an emotional valence map in the limbic forebrain by TAI-FISH. Nat Neurosci 17:1552-1559. CrossRef Medline

Yawata S, Yamaguchi T, Danjo T, Hikida T, Nakanishi S (2012) Pathwayspecific control of reward learning and its flexibility via selective dopamine receptors in the nucleus accumbens. Proc Natl Acad Sci U S A 109: 12764-12769. CrossRef Medline 